\title{
Clinicopathologic Features of Submucosal Papillary Gastric Cancer Differ from Those of Other Differentiated-Type Histologies
}

\author{
Seung Yong Shin ${ }^{1,2}$, Jie-Hyun Kim¹, Myeong-Cherl Kook ${ }^{3}$, Do Youn Park ${ }^{4,5}$, Keun Won Ryu', II Ju Choi \\ Sung Hoon $\mathrm{Noh}^{8}$, Hyunki Kim${ }^{9}$, and Yong Chan Lee ${ }^{10}$ \\ ${ }^{1}$ Department of Internal Medicine, Gangnam Severance Hospital, Yonsei University College of Medicine, ${ }^{2}$ Department of Internal \\ Medicine, Chung-Ang University Hospital, Chung-Ang University College of Medicine, Seoul, ${ }^{3}$ Department of Pathology, Center for \\ Gastric Cancer, National Cancer Center, Goyang, ${ }^{4}$ Department of Pathology, Pusan National University Hospital, Pusan National \\ University School of Medicine, ${ }^{5}$ St. Maria Pathology Laboratory, Busan, Departments of ${ }^{6}$ Surgery and ${ }^{7}$ Internal Medicine, Center for \\ Gastric Cancer, National Cancer Center, Goyang, Departments of ${ }^{8}$ Surgery, ${ }^{9}$ Pathology, and ${ }^{10}$ Internal Medicine, Severance Hospital, \\ Yonsei University College of Medicine, Seoul, Korea
}

\section{Article Info}

Received October 2, 2019

Revised January 19, 2020

Accepted January 21, 2020

Published online April 17, 2020

\section{Corresponding Author}

Jie-Hyun Kim

ORCID https://orcid.org/0000-0002-9198-3326

E-mail otilia94@yuhs.ac

Myeong-Cherl Kook

ORCID https://orcid.org/0000-0002-3435-3301

E-mail mckook@ncc.re.kr

Do Youn Park

ORCID https://orcid.org/0000-0001-7641-1509

E-mail pdy220@pusan.ac.kr

\section{Hyunki Kim}

ORCID https://orcid.org/0000-0003-2292-5584

E-mail kimhyunki@yuhs.ac
Background/Aims: Papillary gastric cancer (GC) is classified as differentiated adenocarcinoma, together with well-differentiated (WD) and moderately differentiated (MD) adenocarcinoma. This study evaluated the risk of lymph node metastasis (LNM) in submucosal (SM) invasive papillary GC compared with other differentiated early GC types.

Methods: This retrospective study involved three tertiary hospitals and enrolled 1,798 lesions with differentiated SM invasive GC treated with curative gastrectomy between March 2001 and December 2012. All pathology slides were reviewed, and clinicopathologic findings associated with LNM, including tumor size, location, gross type, ulceration, depth and width of SM invasion, and lymphovascular invasion (LVI), were analyzed.

Results: The proportion of SM papillary GC was $2.8 \%(n=51)$. SM papillary GC was associated with larger tumor size and deeper and wider SM invasion than other differentiated GC types. LNM was significantly higher in the papillary type than in the MD and WD types. LNM was found in $27.5 \%$ of SM papillary GC patients (WD: $9.0 \%$, MD: $21.2 \%$ ). LVI was the only significant risk factor for LNM in SM papillary GC. The depth or width of SM invasion was not associated with LNM in papillary GC. Lower third location or elevated gross appearance was significantly associated with LVI.

Conclusions: SM papillary GC had the highest LNM rate, with features different from those of other differentiated SM invasive GCs. The treatment strategy for SM papillary GC should be carefully approached, especially for lesions located in the lower third or of the elevated gross type. (Gut Liver 2021;15:44-52)

Key Words: Stomach neoplasm; Adenocarcinoma, papillary; Lymphatic metastasis; Risk factors

\section{INTRODUCTION}

Papillary adenocarcinoma is a rare histologic subtype of gastric cancer (GC). It is characterized histologically by well-differentiated (WD) structures and epithelial projections scaffolded by a central fibrovascular core. ${ }^{1}$ Papillary adenocarcinoma is classified as differentiated-type GC, together with WD and moderately differentiated (MD) tubular adenocarcinoma in the Japanese classification, and as intestinal type cancer in the Lauren classification. ${ }^{2,3}$ However, recent studies have reported that papillary early gastric cancer (EGC) has a higher rate of lymph node metastasis (LNM) and liver metastasis, and a lower overall 5-year survival rate compared to that in other differentiated EGC types. ${ }^{1,4-7}$ As a result, although papillary EGC can be treated with endoscopic submucosal dissection (ESD) when lesions meet the expanded criteria, the application of these criteria to papillary EGC is questionable, with con- 
cern due to the high rate of LNM in papillary EGC.,

Submucosal (SM) invasion is a risk factor associated with LNM. $^{10}$ Compared with mucosal invasion alone, SM invasive EGC has been found to have a higher LNM rate, ${ }^{11,12}$ and the expanded ESD criteria consider SM invasion depth as an important factor in deciding whether or not to perform ESD. ${ }^{13,14}$ ESD has been performed for SM invasive differentiated GC using the expanded criteria. However, the rate of LNM remains at approximately $4 \%,{ }^{15,16}$ and several efforts have been made to identify the factors predicting LNM in SM invasive differentiated GC. Some authors found that the presence of a poorly differentiated carcinoma component in the SM layer of a differentiated GC was an independent risk factor for LNM. ${ }^{17}$ The width of SM invasion and the superficial tumor size ratio were also suggested as risk factors predicting LNM in patients with SM invasive differentiated GC who meet the expanded criteria. ${ }^{18}$

Papillary EGC has a significantly higher frequency of SM invasion compared to that in other differentiated EGC types. ${ }^{8,9}$ The reported SM invasion rates were $41.4 \%$ in ESD specimens and $71.4 \%$ in surgical specimens, and were higher than those of other differentiated GC (17.1\% and $50.8 \%){ }^{8,19}$ Thus, detailed analysis of SM invasive features such as a minor poorly differentiated component or SM invasion width may be helpful in predicting the risk of LNM in SM invasive papillary GC. However, the factors predictive of LNM in SM invasive papillary GC have not been identified. Considering the high SM invasion and LNM rates, predicting LNM in SM invasive papillary GC is crucial for optimal treatment and prevention of unnecessary ESD. ${ }^{20,21}$ Therefore, this study aimed to identify the clinicopathologic features and factors associated with LNM in SM papillary EGC.

\section{MATERIALS AND METHODS}

\section{Study design}

This study was approved by the institutional review boards of Severance Hospital, Pusan National University Hospital, and the National Cancer Center (Severance Hospital approval number: 4-2015-0688, Pusan National University Hospital approval number: PNUH2013-3, and National Cancer Center approval number: NCC2016-0072). This multicenter retrospective study involved three tertiary hospitals in South Korea (Severance Hospital, Pusan National University Hospital, and the National Cancer Center). The medical records and pathology slides of patients who were diagnosed with differentiated SM invasive GC and underwent curative gastrectomy between March 2001 and December 2012 were collected. The patients with mul- tiple GC were excluded from this study. Furthermore, we did not enroll the patients undergoing additional gastrectomy following non-curative endoscopic resection. A total of 2,461 patient slides were enrolled, 601 of which were excluded due to inadequate quality for analysis; after pathological review, an additional 62 were excluded because they did not meet enrolment criteria. Finally, 1,798 patient slides were selected for the study, and the pathological and clinical data of each patient were analyzed. Researchers at each institution applied and confirmed the same criteria for pathological review through periodic communication. This study is a retrospective study using medical record review and so informed consent was waived.

\section{Patients and clinicopathologic evaluation}

Clinicopathologic characteristics were evaluated using medical records, and the pathology slides were reanalyzed by a pathologist at each institution. All surgical specimens were fixed in 5\% (v/v) formaldehyde and tumors and surrounding normal tissues were embedded in paraffin. Tissue blocks were sliced with a thickness of $4 \mathrm{~mm}$, and each sectioned tissue block was stained with hematoxylin and eosin prior to light microscopy. Experienced gastrointestinal pathologists at each institution (H.K., M.C.K., and D.Y.P.) reanalyzed all pathology slides in the same manner.

Papillary EGC was defined as a tumor in which more than $50 \%$ of the tumor area contained papillary structures, as confirmed by a pathologist. Gross appearance of tumor was classified using the criteria of the Japanese Gastric Cancer Association, ${ }^{22}$ and tumors were divided into two groups. Protruding type (type I) and superficially-elevated type (type IIa) were classified as elevated, and other types as non-elevated. We also divided longitudinal tumor location as lower (antrum, prepylorus, and pylorus), and other (upper and middle). The maximum horizontal diameter of SM layer invasion was defined as the invasion width. ${ }^{18}$ We measured the depth of invasion from the lowest point of an imaginary line in continuity with the adjacent muscularis mucosa to the point of deepest tumor penetration. ${ }^{23}$ Ulcer formation was defined as deformity of the muscularis mucosa or fibrosis evident in the SM layer. The poorly differentiated carcinoma component in the SM layer was measured and was considered present when it constituted $>5 \%$ of the layer. ${ }^{17}$ The tumor was categorized according to expanding (definite margin distinct from surrounding tissue) or infiltrative (no definite margin) patterns. ${ }^{24} \mathrm{We}$ identified the rate of LNM in SM invasive papillary GCs for comparison with the rate in other differentiated-type SM invasive GC. The clinicopathologic factors associated with LNM were evaluated through review of medical records and pathology specimens. 


\section{Statistical analysis}

The Pearson chi-square test was used for categorical variables. The Student t-test was used to compare the means of continuous variables, and continuous variables are presented as the mean \pm standard deviation. Variables that were significant in the univariate analysis were subsequently tested in the multivariate logistic regression analysis. Irrespective of the results of the univariate analysis, potential variables that could influence the result were also included in the multivariate analysis. For all comparisons, two-sided p-values $<0.05$ were considered statistically significant. Statistical analyses were performed using SPSS version 18.0 (SPSS Inc., Chicago, IL, USA).

Table 1. Clinicopathologic Characteristics of Papillary and Other Differentiated Submucosal Gastric Cancers

\begin{tabular}{|c|c|c|c|}
\hline Characteristic & $\begin{array}{l}\text { Papillary } \\
\text { (n=51) }\end{array}$ & $\begin{array}{l}\text { WD or MD } \\
(n=1,747)\end{array}$ & p-value \\
\hline Age, yr & $66.8 \pm 8.8$ & $62.6 \pm 9.3$ & 0.002 \\
\hline Male sex & 38 (74.5) & $1,352(77.4)$ & 0.628 \\
\hline Tumor size, $\mathrm{cm}$ & $3.9 \pm 2.0$ & $3.1 \pm 1.8$ & 0.001 \\
\hline SM invasion depth, $\mu \mathrm{m}$ & $2,801.7 \pm 2,239.4$ & $1,700.3 \pm 1,431.3$ & 0.001 \\
\hline SM invasion width, mm & $10.9 \pm 8.2$ & $5.7 \pm 5.2$ & $<0.001$ \\
\hline Location & & & 0.822 \\
\hline Upper\&middle & $24(46.0)$ & 855 (48.8) & \\
\hline Lower & $27(54.0)$ & 892 (51.2) & \\
\hline Gross appearance & & & $<0.001$ \\
\hline Non-elevated & $10(19.6)$ & $1,148(65.7)$ & \\
\hline Elevated & $41(80.4)$ & 599 (34.3) & \\
\hline Ulcer formation & & & 0.049 \\
\hline Absent & $41(80.4)$ & $1,161(66.5)$ & \\
\hline Present & 10 (19.5) & 586 (33.5) & \\
\hline Infiltrative pattern & & & 0.519 \\
\hline Expanding & $44(86.3)$ & $1,447(82.8)$ & \\
\hline Infiltrative & $7(13.7)$ & $300(17.2)$ & \\
\hline \multicolumn{2}{|c|}{ PD component in submucosal layer } & & 0.089 \\
\hline No & 44 (86.3) & $1,328(76.0)$ & \\
\hline Yes & $7(13.7)$ & $419(24.0)$ & \\
\hline LVI & & & 0.005 \\
\hline Absent & 26 (51.0) & 1,214 (69.5) & \\
\hline Present & 25 (49.0) & 533 (30.5) & \\
\hline PNI & & & 0.248 \\
\hline Absent & 48 (94.1) & $1,684(96.4)$ & \\
\hline Present & 3 (5.9) & $63(3.6)$ & \\
\hline LNM & & & 0.057 \\
\hline Absent & 37 (72.5) & 1,455 (83.3) & \\
\hline Present & 14 (27.5) & 292 (16.7) & \\
\hline
\end{tabular}

Data are presented as mean \pm SD or number (\%).

WD, well-differentiated; MD, moderately differentiated; SM, submucosal; PD, poorly differentiated; LVI, lymphovascular invasion; PNI, perineural invasion; LNM, lymph node metastasis.
RESULTS

\section{Clinicopathologic characteristics compared between papillary and other differentiated SM invasive GC types}

The incidence of papillary-type GC in differentiated SM invasive GCs was $2.8 \%(\mathrm{n}=51)$. Table 1 summarizes the clinicopathologic characteristics of papillary and other differentiated-type GC including WD/MD. The mean age of patients with SM papillary GC was $66.8 \pm 8.8$ years with male predominance. SM papillary GCs were significantly larger $(3.9 \pm 2.0 \mathrm{~cm}$ vs $3.1 \pm 1.8 \mathrm{~cm}, \mathrm{p}=0.001)$, with more elevated appearance $(80.4 \%$ vs $34.3 \%, \mathrm{p}<0.001)$ and less frequent ulcer formation ( $19.5 \%$ vs $33.5 \%, \mathrm{p}=0.049)$ than other differentiated SM invasive GCs. The SM invasion depth was greater $(2,801.7 \pm 2,239.4 \mu \mathrm{m}$ vs $1,700.3 \pm 1,431.3$ $\mu \mathrm{m}, \mathrm{p}=0.001)$ and the $\mathrm{SM}$ invasion width was wider $(10.9 \pm 8.2 \mathrm{~mm}$ vs $5.7 \pm 5.2 \mathrm{~mm}, \mathrm{p}<0.001)$ in SM papillary GC cases compared with other differentiated SM invasive GCs. Lymphovascular invasion (LVI) was more frequent in SM papillary GC cases $(49.0 \%$ vs $30.5 \%, \mathrm{p}=0.005)$.

\section{LNM according to subtype of differentiated SM invasive GC}

LNM rate tended to be higher in papillary GC (27.5\%) than that of other differentiated GCs (16.7\%), but the difference did not reach the statistical significance $(\mathrm{p}=0.057)$ (Table 1). However, among the three subtypes classified as $\mathrm{WD}, \mathrm{MD}$, and papillary GC, SM papillary GC showed the highest LNM rate (Table 2). The risk of LNM was increased in order of SM invasive WD, MD, and papillary GC (WD: reference; MD: odds ratio [OR], 2.725; 95\% confidence interval [CI], 2.003 to 3.707; $\mathrm{p}<0.001$; papillary: OR, 3.844; 95\% CI, 1.962 to 7.530 ; $\mathrm{p}<0.001$ ).

\section{Predictive factors associated with LNM in SM invasive papillary GC}

In the univariate analysis, LVI was the only factor significantly associated with LNM in SM papillary GC. SM papillary GC with LVI was more significantly found in the positive LNM group ( $35.1 \%$ vs $85.7 \%$, $\mathrm{p}=0.001$ ). For the multivariate analysis, we determined the cutoff values

Table 2. Lymph Node Metastasis Rates According to Subtype in Differentiated Submucosal Gastric Cancers

\begin{tabular}{lccc}
\hline & OR $(95 \% \mathrm{Cl})$ & $\beta$ & $p$-value \\
\hline WD $(\mathrm{n}=636)$ & Reference & & \\
MD $(\mathrm{n}=1,111)$ & $2.725(2.003-3.707)$ & 1.002 & $<0.001$ \\
Papillary $(\mathrm{n}=51)$ & $3.844(1.962-7.530)$ & 1.346 & $<0.001$ \\
\hline
\end{tabular}

$\mathrm{OR}$, odds ratio; $\mathrm{Cl}$, confidence interval; $\mathrm{WD}$, well-differentiated; $\mathrm{MD}$, moderately differentiated. 
of continuous variables. The cutoff values for tumor size and depth of SM invasion were determined according to the expanded ESD criteria. The cutoff value for width of SM invasion was set to $9 \mathrm{~mm}$, which was associated with the largest area under the receiver operating characteristic curve. As a result, LVI was also an independent factor associated with LNM in multivariate analysis (OR, 11.148; $95 \% \mathrm{CI}, 2.028$ to $61.282 ; \mathrm{p}=0.006$ ). Including one negative LVI case meeting the expanded ESD criteria (tumor diameter $\leq 3 \mathrm{~cm}$ and tumor depth from the muscularis mucosa $<500 \mu \mathrm{m}$ ), no LNM was found. Conversely, tumor size, SM invasion depth and width, and perineural invasion were not significantly associated with LNM in both univariate and multivariate analyses. Predictive factors associated with LNM in SM papillary GC are summarized in Table 3.

\section{Predictive factors associated with LVI in SM invasive papillary GC}

No significant factor was found to be associated with LVI in univariate analysis (Table 4). In the multivariate analysis, SM papillary GC with lower third location (OR, 4.218; 95\% CI, 1.111 to $16.008 ; \mathrm{p}=0.034)$, and elevated morphologic type (OR, 7.552; 95\% CI, 1.178 to 48.427 ; $\mathrm{p}=0.033$ ) were independent factors associated with LVI in SM papillary GC. Other factors were not associated with LVI. Predictive factors associated with LVI in SM papillary GC are summarized in Table 4.

\section{DISCUSSION}

SM invasive GC has a higher LNM rate than mucosal GC, ${ }^{25,26}$ and assessment of LNM has been important for the

Table 3. Univariate and Multivariate Analyses of Clinicopathological Characteristics Associated with LNM in Submucosal Papillary Gastric Cancer

\begin{tabular}{|c|c|c|c|c|c|}
\hline Variable & No LNM (n=37) & LNM (n=14) & $p$-value & OR $(95 \% \mathrm{Cl})$ & $\mathrm{p}$-value \\
\hline Age, yr & $66.5 \pm 9.6$ & $67.3 \pm 6.3$ & 0.778 & - & - \\
\hline Male sex & $29(78.4)$ & $9(64.3)$ & 0.303 & - & - \\
\hline Tumor size & & & 0.214 & - & - \\
\hline$\leq 3 \mathrm{~cm}$ & $14(37.8)$ & $8(57.1)$ & & & \\
\hline$>3 \mathrm{~cm}$ & 23 (62.2) & $6(42.9)$ & & & \\
\hline SM invasion depth & & & 0.401 & - & - \\
\hline$<500 \mu \mathrm{m}$ & $6(16.2)$ & $1(7.1)$ & & & \\
\hline$\geq 500 \mu \mathrm{m}$ & 31 (83.8) & 13 (92.9) & & & \\
\hline SM invasion width & & & 0.475 & - & - \\
\hline$\leq 9 \mathrm{~mm}$ & 17 (45.9) & $8(57.1)$ & & & \\
\hline$>9 \mathrm{~mm}$ & $20(54.1)$ & $6(42.9)$ & & & \\
\hline Tumor location & & & 0.223 & - & - \\
\hline Upper\&middle & 20 (52.8) & $4(28.6)$ & & & \\
\hline Lower & $17(47.2)$ & $10(71.4)$ & & & \\
\hline Gross appearance & & & 0.321 & - & - \\
\hline Non-elevated & $6(16.2)$ & $4(28.6)$ & & & \\
\hline Elevated & 31 (83.8) & $10(71.4)$ & & & \\
\hline Ulcer formation & & & 0.075 & - & - \\
\hline No & $32(86.5)$ & $9(64.3)$ & & & \\
\hline Yes & $5(13.5)$ & $5(35.7)$ & & & \\
\hline Infiltrative pattern & & & 0.325 & - & - \\
\hline Expanding & 33 (89.2) & $11(78.6)$ & & & \\
\hline Infiltrative & $4(10.8)$ & $3(21.4)$ & & & \\
\hline PD component in submucosal layer & & & 0.943 & - & - \\
\hline No & $32(86.5)$ & $12(85.7)$ & & & \\
\hline Yes & $5(13.5)$ & $2(14.3)$ & & & \\
\hline LVI & & & 0.001 & & 0.006 \\
\hline No & 24 (64.9) & $2(14.3)$ & & Reference & \\
\hline Yes & $13(35.1)$ & $12(85.7)$ & & $\begin{array}{c}11.148 \\
(2.028-61.282)\end{array}$ & \\
\hline PNI & & & 0.814 & - & - \\
\hline No & $35(94.6)$ & 13 (92.9) & & & \\
\hline Yes & $2(5.4)$ & $1(7.1)$ & & & \\
\hline
\end{tabular}

Data are presented as mean \pm SD or number (\%).

LNM, lymph node metastasis; OR, odds ratio; Cl, confidence interval; SM, submucosal; PD, poorly differentiated; LVI, lymphovascular invasion; $\mathrm{PNI}$, perineural invasion. 
Table 4. Univariate and Multivariate Analyses of Clinicopathological Characteristics Associated with LVI in Submucosal Papillary Gastric Cancer

\begin{tabular}{|c|c|c|c|c|c|}
\hline Variable & No LVI (n=26) & LVI (n=25) & $\mathrm{p}$-value & OR $(95 \% \mathrm{CI})$ & $\mathrm{p}$-value \\
\hline Age, yr & $67.4 \pm 10.3$ & $66.1 \pm 7.0$ & 0.602 & - & - \\
\hline Male sex & $17(65.4)$ & $21(84.0)$ & 0.127 & - & - \\
\hline Tumor size & & & 0.210 & - & - \\
\hline$\leq 3 \mathrm{~cm}$ & $9(34.6)$ & 13 (52.0) & & & \\
\hline$>3 \mathrm{~cm}$ & $17(65.4)$ & $12(48.0)$ & & & \\
\hline SM invasion depth, $\mu \mathrm{m}$ & $2,751 \pm 2,853$ & $2,662 \pm 1,749$ & 0.873 & - & - \\
\hline $\mathrm{SM}$ invasion width, $\mathrm{mm}$ & $10.3 \pm 7.3$ & $11.7 \pm 9.2$ & 0.546 & - & - \\
\hline Tumor location & & & 0.084 & & 0.034 \\
\hline Upper\&middle & $15(57.7)$ & $9(36.0)$ & & Reference & \\
\hline Lower & $11(42.3)$ & $16(64.0)$ & & $\begin{array}{c}4.218 \\
(1.111-16.008)\end{array}$ & \\
\hline Gross appearance & & & 0.075 & & 0.033 \\
\hline Non-elevated & $8(30.8)$ & $2(8.0)$ & & Reference & \\
\hline Elevated & 18 (69.2) & $23(92.0)$ & & $\begin{array}{c}7.552 \\
(1.178-48.427)\end{array}$ & \\
\hline Ulcer formation & & & 0.945 & - & - \\
\hline No & 21 (80.8) & $20(80.0)$ & & & \\
\hline Yes & $5(19.2)$ & $5(20.0)$ & & & \\
\hline Infiltrative pattern & & & 0.725 & - & - \\
\hline Expanding & $22(84.6)$ & $22(88.0)$ & & & \\
\hline Infiltrative & $4(15.4)$ & $3(12.0)$ & & & \\
\hline PD component in submucosal layer & & & 0.643 & - & - \\
\hline No & 23 (88.5) & 21 (84.0) & & & \\
\hline Yes & 3 (11.5) & $4(16.0)$ & & & \\
\hline PNI & & & 0.575 & - & - \\
\hline No & 24 (92.3) & $24(96.0)$ & & & \\
\hline Yes & $2(7.7)$ & $1(4.0)$ & & & \\
\hline
\end{tabular}

Data are presented as mean \pm SD or number (\%).

LVI, lymphovascular invasion; OR, odds ratio; Cl, confidence interval; SM, submucosal; PD, poorly differentiated; PNI, perineural invasion.

optimal treatment of SM invasive GC. Several studies have attempted to identify risk factors predicting LNM in patients with SM invasive GC. ${ }^{17,27,28}$ However, despite the high SM invasion rate, the clinicopathologic features and factors predicting LNM have not been evaluated in SM papillary GC. Our multicenter study enrolled subjects from three tertiary hospitals and analyzed the clinicopathologic features and risk factors associated with LNM in SM papillary GC.

In the present study, the incidence of SM papillary GC among differentiated SM invasive GCs was $2.8 \%$. Patients with SM papillary GC were older than patients with other differentiated SM invasive GCs, and there was a male predominance. These demographic characteristics are consistent with that shown in previous studies. ${ }^{4,29}$ SM papillary GC showed more aggressive clinicopathologic features than other differentiated SM invasive GCs. SM papillary GC showed larger size, deeper and wider SM invasion, and higher LVI rate. LNM rate was numerically higher in papillary GC $(27.5 \%)$ than that of other differentiated GCs (16.7\%), but the difference did not reach the statistical significance ( $\mathrm{p}=0.057)$, which is probably related to the small sample size. However, compared with each subtype of differentiated GCs, LNM rate was highest in papillary GC among differentiated SM invasive GCs, and LVI was significantly associated with LNM. Lower third location or elevated gross appearance was predictive of LVI in SM papillary GC.

The invasive pathologic features of papillary EGC have been reported in previous studies. Papillary EGC has been found to have high rates of SM invasion and LVI., ${ }^{8,19,29}$ Min et al. ${ }^{29}$ reported that SM papillary GC has a predominant elevated appearance and a higher LVI rate compared to that in other differentiated SM invasive GCs. In line with these observations, our study found that SM papillary GC is larger and has deeper SM invasion depth than that in other differentiated SM invasive GCs. In addition to SM invasion depth, we also measured the SM invasion width and demonstrated that SM papillary GC has greater invasion width compared to that in other differentiated SM invasive GCs. This is a novel finding in our study. In recent studies, the SM invasion width of cancer was found to be a risk factor for $\mathrm{LNM},{ }^{30}$ and has been suggested as a reason to expand the ESD criteria for curative endoscopic resection 

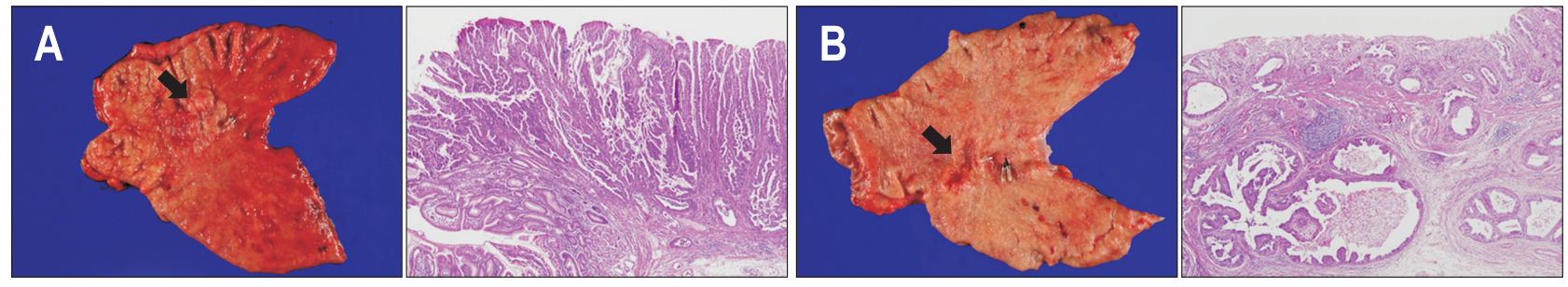

Fig. 1. Clinical cases of pathologically confirmed submucosal invasive papillary gastric cancers (arrow). (A) Elevated lesion with lymphovascular and lymph node invasion $(H \& E, \times 40)$ and $(B)$ non-elevated lesion without lymphovascular and lymph node invasion $(H \& E, \times 40)$.

of SM invasive GC. ${ }^{31}$ Hoteya et al. ${ }^{32}$ suggested that the virtual SM volume index calculated using SM invasion width is correlated with the risk of LVI. Thus, when invading the SM layer, papillary EGC has a more aggressive spreading pattern in both the vertical and horizontal directions.

The invasive pathologic features and high LNM rate of papillary GC have consistently raised a question as to whether the current expanded ESD criteria that are applied to other differentiated EGC could be applied to papillary EGC. ${ }^{8,9,19,29}$ When GC reaches the SM layer, the rate of LNM is approximately $15 \%$ to $20 \%,{ }^{11,12}$ which is higher than that of mucosal GC, at $0.4 \%$ to $3 \%{ }^{33}$ In papillary EGC, including mucosal GC and submucosal GC, the reported prevalence of LNM was approximately $18 \%{ }^{8,9}$ However, our study found that when invading the SM layer, the LNM rate of papillary EGC increased to $25.6 \%$. Compared with SM invasive WD GC, SM papillary GC showed an approximately four times higher rate of LNM (OR, 3.844; 95\% CI, 1.962 to 7.530; $\mathrm{p}<0.001$ ). There were three patients who were within expanded criteria among 51 SM papillary GCs and the rate of LNM in these patients was $33.3 \%(n=1)$ which was also numerically higher than that of other differentiated-type GCs (16.7\%). The application of current expanded ESD criteria for the treatment of papillary EGC is controversial. However, the high LNM rate of SM papillary GC suggests the necessity to evaluate whether the expanded indication for differentiated-type GC is applicable to papillary GCs, at least when the cancer invades the SM layer.

LVI was a predictive factor of LNM in both univariate and multivariate analysis in our study. However, the depth of SM invasion which is known as a predictive factor for LNM in $\mathrm{EGC}^{34}$ showed no significant association with LNM. This is different from other differentiated-type GC, in which depth of invasion was a significant risk factor for LNM (Supplementary Tables 1, 2). These findings therefore need to be interpreted with caution. There was no sufficient evidence to suggest SM invasion depth or width would not affect the risk of LNM because of small sample size and number of events. Further large-scale studies are needed for better understanding the association between
SM invasion and risk of LNM in SM papillary GCs.

LVI predicts clinical outcomes in various malignancies, including GC. ${ }^{35-37}$ Since positive LVI is not only a predictive factor for LNM, but also a cause of non-curative resection, it is essential to predict LVI before ESD. However, LVI is difficult to predict accurately via pretreatment endoscopic examination. Our study showed that lower third location or elevated appearance is significantly associated with a high LVI rate. Although papillary GC tends to occur in the proximal stomach, ${ }^{4,38}$ lower-third location is associated with LVI. At present, it is unclear why these variables are associated with LVI, but the following pathological characteristics may be involved. Lymphatics in the gastric submucosa are known to show rapid postnatal expansion, and develop an abundant network in the gastrointestinal tract. ${ }^{39}$ In patients with atrophic gastritis, in which the mucosal layer becomes thinner, lymphatic capillaries can be found near the surface epithelium. ${ }^{40}$ Atrophic gastritis has been reported to extend from the antrum to the corpus with age. ${ }^{41}$ Considering the predominance of older patients and invasive spreading patterns of SM papillary EGC, the possibility of LVI is assumed to increase in the lower-third area, where the lymphatic capillaries approach the surface epithelium. The pathologic characteristics of papillary GC, including exophytic and projective epithelial growth patterns, are thought to be associated with elevated appearance. ${ }^{1}$ Cancers that grow more outward and form an elevated appearance are more likely to be advanced lesions, and the possibility of LVI may increase in more advanced lesions. Therefore, consideration of LVI and LNM is required when papillary GC suspicious for SM invasion is located in the lower third of the stomach or shows elevated appearance during pretreatment endoscopy. In our study, two cases of SM papillary GC located at lower third area of stomach were within the expanded ESD criteria, and one case (50\%) of them showed LNI and LNM. In addition, four cases of SM papillary GC with elevated appearance were within the expanded ESD criteria, and one case (25\%) of them showed LVI and LNM. Fig. 1 shows the representative gross photographs of elevated and non-elevated papillary adenocarcinomas and their corresponding mi- 
croscopic findings. Further studies are needed to evaluate the mechanism underlying these findings. For more precise prediction of LVI, further analysis with immunohistochemistry can be considered. Recent studies have shown that immunohistochemistry using signaling proteins allows access to the lymphatic and vascular spaces. ${ }^{42,43} \mathrm{Im}$ munohistochemical analysis of resected tissue could improve the predictive accuracy for LVI.

There are several limitations of this study. First, this was a retrospective study. However, experienced gastrointestinal pathologists at each institution reanalyzed all pathology slides in the same manner. Second, a relatively small number of patients were enrolled. There is a risk of finding false positive results as well as false negative results. Third, the width of slices for surgical specimen is different from that for endoscopic resection specimen and the current results may need to be validated. However, this multicenter study involved three tertiary hospitals and focused on SM papillary EGC. Considering the rarity of papillary EGC, the number of patients was adequate for analysis, and careful pathologic analysis of all sliced slides was performed.

In conclusion, although classified as differentiated GC, SM papillary GC had the highest LNM rate, with features different from those of other differentiated SM invasive GCs. SM papillary GC showed larger size, deeper and wider SM invasion, and a higher LVI rate compared to other differentiated SM invasive GCs. LVI was an independent risk factor for LNM in SM papillary GC, and the lowerthird location or elevated appearance was significantly associated with LVI. The treatment strategy should be carefully approached for SM papillary GC.

\section{CONFLICTS OF INTEREST}

No potential conflict of interest relevant to this article was reported.

\section{ACKNOWLEDGEMENTS}

This research was supported by the Basic Science Research Program through the National Research Foundation of Korea (NRF) funded by the Ministry of Education, Science and Technology (grant number: 2015R1C1A2A01053924).

\section{AUTHOR CONTRIBUTIONS}

Conceptualization: J.K., M.K., D.Y.P., H.K. Data curation: S.Y.S. Formal analysis: S.Y.S., J.K. Methodology: J.K.,
M.K., D.Y.P., H.K., K.W.R., S.H.N. Project administration: J.K. Visualization: S.Y.S. Writing - original draft: S.Y.S. Writing - review \& editing: J.K., M.K., D.Y.P., H.K., I.J.C., Y.C.L. Approval of final manuscript: all authors.

\section{ORCID}

Seung Yong Shin https://orcid.org/0000-0001-8970-2444 Jie-Hyun Kim https://orcid.org/0000-0002-9198-3326 Myeong-Cherl Kook

https://orcid.org/0000-0002-3435-3301

Do Youn Park https://orcid.org/0000-0001-7641-1509

Keun Won Ryu https://orcid.org/0000-0002-5935-9777

Il Ju Choi https://orcid.org/0000-0002-8339-9824

Sung Hoon Noh https://orcid.org/0000-0003-4386-6886

Hyunki Kim https://orcid.org/0000-0003-2292-5584

Yong Chan Lee https://orcid.org/0000-0001-8800-6906

\section{REFERENCES}

1. Hu B, El Hajj N, Sittler S, Lammert N, Barnes R, Meloni-Ehrig A. Gastric cancer: classification, histology and application of molecular pathology. J Gastrointest Oncol 2012;3:251261.

2. Japanese Gastric Cancer Association. Japanese classification of gastric carcinoma: 3rd English edition. Gastric Cancer 2011;14:101-112.

3. Lauren P. The two histological main types of gastric carcinoma: diffuse and so-called intestinal-type carcinoma. An attempt at a histo-clinical classification. Acta Pathol Microbiol Scand 1965;64:31-49.

4. Yasuda K, Adachi Y, Shiraishi N, Maeo S, Kitano S. Papillary adenocarcinoma of the stomach. Gastric Cancer 2000;3:3338.

5. Sekiguchi M, Sekine S, Oda I, et al. Risk factors for lymphatic and venous involvement in endoscopically resected gastric cancer. J Gastroenterol 2013;48:706-712.

6. Sekiguchi M, Kushima R, Oda I, et al. Clinical significance of a papillary adenocarcinoma component in early gastric cancer: a single-center retrospective analysis of 628 surgically resected early gastric cancers. J Gastroenterol 2015;50:424434.

7. Koseki K, Takizawa T, Koike M, Ito M, Nihei Z, Sugihara K. Distinction of differentiated type early gastric carcinoma with gastric type mucin expression. Cancer 2000;89:724-732.

8. Lee HJ, Kim GH, Park DY, et al. Endoscopic submucosal dissection for papillary adenocarcinoma of the stomach: is it really safe? Gastric Cancer 2017;20:978-986.

9. Lee HJ, Kim GH, Park DY, et al. Is endoscopic submucosal 
dissection safe for papillary adenocarcinoma of the stomach? World J Gastroenterol 2015;21:3944-3952.

10. Roviello F, Rossi S, Marrelli D, et al. Number of lymph node metastases and its prognostic significance in early gastric cancer: a multicenter Italian study. J Surg Oncol 2006;94:275280.

11. Sano T, Sasako M, Kinoshita T, Maruyama K. Recurrence of early gastric cancer: follow-up of 1475 patients and review of the Japanese literature. Cancer 1993;72:3174-3178.

12. Maruyama K, Gunvén P, Okabayashi K, Sasako M, Kinoshita T. Lymph node metastases of gastric cancer. General pattern in 1931 patients. Ann Surg 1989;210:596-602.

13. Gotoda T, Yanagisawa A, Sasako M, et al. Incidence of lymph node metastasis from early gastric cancer: estimation with a large number of cases at two large centers. Gastric Cancer 2000;3:219-225.

14. Yamaguchi N, Isomoto H, Fukuda E, et al. Clinical outcomes of endoscopic submucosal dissection for early gastric cancer by indication criteria. Digestion 2009;80:173-181.

15. Jee YS, Hwang SH, Rao J, et al. Safety of extended endoscopic mucosal resection and endoscopic submucosal dissection following the Japanese Gastric Cancer Association treatment guidelines. Br J Surg 2009;96:1157-1161.

16. Kang HJ, Kim DH, Jeon TY, et al. Lymph node metastasis from intestinal-type early gastric cancer: experience in a single institution and reassessment of the extended criteria for endoscopic submucosal dissection. Gastrointest Endosc 2010;72:508-515.

17. Jung DH, Bae YS, Yoon SO, et al. Poorly differentiated carcinoma component in submucosal layer should be considered as an additional criterion for curative endoscopic resection of early gastric cancer. Ann Surg Oncol 2015;22 Suppl 3:S772-S777.

18. Choi JY, Park YS, Jung HY, et al. Identifying predictors of lymph node metastasis after endoscopic resection in patients with minute submucosal cancer of the stomach. Surg Endosc 2015;29:1476-1483

19. Kim TS, Min BH, Kim KM, Lee JH, Rhee PL, Kim JJ. Endoscopic submucosal dissection for papillary adenocarcinoma of the stomach: low curative resection rate but favorable long-term outcomes after curative resection. Gastric Cancer 2019;22:363-368.

20. Kim YI, Kim YA, Kim CG, et al. Serial intermediate-term quality of life comparison after endoscopic submucosal dissection versus surgery in early gastric cancer patients. Surg Endosc 2018;32:2114-2122.

21. Toyonaga T, Man-i M, East JE, et al. 1,635 Endoscopic submucosal dissection cases in the esophagus, stomach, and colorectum: complication rates and long-term outcomes. Surg Endosc 2013;27:1000-1008.

22. Endoscopic Classification Review Group. Update on the paris classification of superficial neoplastic lesions in the digestive tract. Endoscopy 2005;37:570-578.

23. Kim JY, Kim WG, Jeon TY, et al. Lymph node metastasis in early gastric cancer: evaluation of a novel method for measuring submucosal invasion and development of a nodal predicting index. Hum Pathol 2013;44:2829-2836.

24. Kim H, Kim JH, Lee YC, et al. Growth patterns of signet ring cell carcinoma of the stomach for endoscopic resection. Gut Liver 2015;9:720-726.

25. An JY, Baik YH, Choi MG, Noh JH, Sohn TS, Kim S. Predictive factors for lymph node metastasis in early gastric cancer with submucosal invasion: analysis of a single institutional experience. Ann Surg 2007;246:749-753.

26. Hölscher AH, Drebber U, Mönig SP, Schulte C, Vallböhmer D, Bollschweiler E. Early gastric cancer: lymph node metastasis starts with deep mucosal infiltration. Ann Surg 2009;250:791-797.

27. Kim JH, Lee YC, Kim H, et al. Additive lymph node dissection may be necessary in minute submucosal cancer of the stomach after endoscopic resection. Ann Surg Oncol 2012;19:779-785.

28. Eom BW, Yu JS, Ryu KW, et al. Optimal submucosal invasion of early gastric cancer for endoscopic resection. Ann Surg Oncol 2015;22:1806-1812.

29. Min BH, Byeon SJ, Lee JH, et al. Lymphovascular invasion and lymph node metastasis rates in papillary adenocarcinoma of the stomach: implications for endoscopic resection. Gastric Cancer 2018;21:680-688.

30. Masaki T, Sugiyama M, Matsuoka H, et al. Clinical utility of grading criteria for submucosal invasion in the prognosis of T1 colorectal carcinomas. J Gastroenterol 2003;38:37-44.

31. Sanomura Y, Oka S, Tanaka S, et al. Predicting the absence of lymph node metastasis of submucosal invasive gastric cancer: expansion of the criteria for curative endoscopic resection. Scand J Gastroenterol 2010;45:1480-1487.

32. Hoteya S, Yamashita S, Kikuchi D, et al. Endoscopic submucosal dissection for submucosal invasive gastric cancer and curability criteria. Dig Endosc 2011;23:30-36.

33. Adachi Y, Shiraishi N, Kitano S. Modern treatment of early gastric cancer: review of the Japanese experience. Dig Surg 2002;19:333-339.

34. Amano Y, Ishihara S, Amano K, et al. An assessment of local curability of endoscopic surgery in early gastric cancer without satisfaction of current therapeutic indications. Endoscopy 1998;30:548-552.

35. Talamonti MS, Kim SP, Yao KA, et al. Surgical outcomes of patients with gastric carcinoma: the importance of primary tumor location and microvessel invasion. Surgery 2003;134:720-727.

36. Chambers WM, Khan U, Gagliano A, Smith RD, Sheffield J, Nicholls RJ. Tumour morphology as a predictor of outcome 
after local excision of rectal cancer. Br J Surg 2004;91:457459.

37. Maehara Y, Kabashima A, Koga T, et al. Vascular invasion and potential for tumor angiogenesis and metastasis in gastric carcinoma. Surgery 2000;128:408-416.

38. Yu H, Fang C, Chen L, et al. Worse prognosis in papillary, compared to tubular, early gastric carcinoma. J Cancer 2017;8:117-123.

39. Saban MR, Mémet S, Jackson DG, et al. Visualization of lymphatic vessels through NF-kappaB activity. Blood 2004;104:3228-3230.

40. Listrom MB, Fenoglio-Preiser CM. Lymphatic distribution of the stomach in normal, inflammatory, hyperplastic, and neoplastic tissue. Gastroenterology 1987;93:506-514

41. Kimura K. Chronological transition of the fundic-pyloric border determined by stepwise biopsy of the lesser and greater curvatures of the stomach. Gastroenterology 1972;63:584-592.

42. Kabashima A, Maehara Y, Kakeji Y, Baba H, Koga T, Sugimachi K. Clinicopathological features and overexpression of matrix metalloproteinases in intramucosal gastric carcinoma with lymph node metastasis. Clin Cancer Res 2000;6:35813584.

43. Persad S, Dedhar S. The role of integrin-linked kinase (ILK) in cancer progression. Cancer Metastasis Rev 2003;22:375384. 